\title{
Leaf Litter Decomposition and Nutrient Dynamics Associated with Common Horticultural Cropland Agroforest Tree Species of Bangladesh
}

\author{
Md. Hasanuzzaman and Mahmood Hossain \\ Forestry and Wood Technology Discipline, Khulna University, Khulna 9208, Bangladesh \\ Correspondence should be addressed to Md. Hasanuzzaman; hasanfwt@gmail.com
}

Received 21 February 2014; Revised 24 April 2014; Accepted 10 May 2014; Published 4 June 2014

Academic Editor: Kristiina Vogt

Copyright @ $2014 \mathrm{Md}$. Hasanuzzaman and M. Hossain. This is an open access article distributed under the Creative Commons Attribution License, which permits unrestricted use, distribution, and reproduction in any medium, provided the original work is properly cited.

\begin{abstract}
Mangifera indica, Zizyphus jujuba, Litchi chinensis, and Artocarpus heterophyllus are the most common cropland agroforest horticultural tree species of Bangladesh. This study focused on leaf litter decomposition and nutrient (N, P, and K) dynamics during the decomposition process. This experiment was conducted for 180 days by using litter bag technique during dry and wet seasons. Mass loss was the highest (49\% and 57\%) for A. heterophyllus and the lowest (25\%) was found for L. chinensis. The highest initial rates $(0.75 \%$ and $2.35 \% /$ day) of decomposition were observed for Z. jujuba and the lowest $(0.50 \%$ and $0.79 \% /$ day) for $L$. chinensis. The highest decay constant was observed for A. heterophyllus (2.14 and 2.34) and the lowest (0.88 and 0.94) for L. chinensis. Leaf litter of all the studied species showed a similar pattern $(\mathrm{K}>\mathrm{N}>\mathrm{P})$ of nutrient release during the decomposition process. Zizyphus jujuba showed comparatively higher return of $\mathrm{N}, \mathrm{P}$, and $\mathrm{K}$ than others. However, a significant $(P<0.05)$ higher amount of mass loss, rate of decomposition, decay constant, and amount of nutrient return from leaf litter were observed during the wet season.
\end{abstract}

\section{Introduction}

Bangladesh is a developing country where agriculture is the major economic activity. Farmers plant trees in the croplands for the increased production of timber, fodder, fuel wood, fruits, herbal medicines, raw material for small cottage industries, and short-term nontimber products and for environmental and ecological benefits [1-4]. Agroforestry promotes more efficient cycling of nutrients than traditional agriculture systems. It is also more sustainable and better for the environment [5-7]. A wide variety of horticultural tree species are used in different croplands and/or forms of agroforestry in Bangladesh [8-10].

Nutrients are uptaken by plants for their growth and development and a portion of these nutrients is accumulated in plant body [11, 12]. Conversely, a considerable amount of nutrients are returned to the soil through litter fall which has an important role in the biogeochemical cycling of nutrients $[13,14]$. Litter improves soil quality through adding the organic matter and nutrients to the soil [15-17]. Leaf litter is the main and fastest source of organic matter and nutrient to the soil compared to other litter types $[6,18$, 19]. The nutrients in litter were added to the soil through microbial decomposition and physical leaching of soluble components followed by microbial oxidation of refractory components [18, 20-22]. However, the amount of nutrient addition through litter decomposition varies from species to species $[20,23,24]$. The amount of nutrient addition to a particular ecosystem was found to vary with the species [20, $25]$ and other climatic conditions [13, 20, 26]. Appropriate tree species selection based on nutrient cycling is a vital issue in agroforestry practice. However, no attempt has been taken to screen or prioritize the commonly planted tree species in the cropland agroforests as well as other types of agroforestry on the basis of nutrient cycling. The objectives of this study were to determine the following: (1) leaf litter decomposition rates for four commonly planted horticultural agroforestry tree species (Artocarpus heterophyllus, Mangifera indica, Zizyphus jujuba, and Litchi chinensis) in the dry season (from December to May with average monthly rainfall of 
$45 \mathrm{~mm}$ ) and wet season (from June to November with average monthly rainfall of $240 \mathrm{~mm}$ ), (2) return rates of $\mathrm{N}, \mathrm{P}$, and $\mathrm{K}$ to the soil for these species in the dry and wet seasons, and (3) the best species to use on the basis of nutrient return through leaf litter decomposition.

\section{Materials and Methods}

2.1. Description of the Study Area. Bangladesh is bordered by the Bay of Bengal on the south and India on all the other sides except for a small section of Myanmar. Southwestern Bangladesh is low ( $<10 \mathrm{~m}$ above mean sea level), flat, and located on a fertile deltaic plain which is predominated by calcareous to noncalcareous alluvium soils [27]. This study was conducted in a selected cropland without trees (paddy field) of Khulna district in southwestern Bangladesh lying between $22^{\circ} 46^{\prime}$ and $22^{\circ} 47^{\prime} \mathrm{N}$ and $89^{\circ} 29^{\prime}$ and $89^{\circ} 30^{\prime}$ E. During the period of experiment no agricultural cultivation was carried out in that cropland. A tropical to subtropical monsoon climate characterizes this region with three distinct seasons, that is, summer (March-May), rainy (June-October), and winter (November-February). The monthly average rainfall is $155 \mathrm{~mm}$. The highest average rainfall (339 $\mathrm{mm})$ occurs from June to September and the lowest average rainfall $(16 \mathrm{~mm})$ occurs in the months of November to February. January is the coldest month and May is the warmest month. The mean annual temperature is $26^{\circ} \mathrm{C}$ with a range of $22-31^{\circ} \mathrm{C}$ [28]. The average relative humidity is the highest $(86 \%-88 \%)$ from July to August and the lowest (72\%-74\%) from February to April.

2.2. Collection and Processing of Leaf Samples. Yellowish senescent leaves of A. heterophyllus, M. indica, Z. jujuba, and L. chinensis were picked from the trees of selected cropland agroforests. Leaves of individual species were thoroughly mixed.

2.3. Experimental Design. Decomposition of leaf litter was determined using the litter bag technique [6]. Five $g$ of air dried leaf litter was placed in each $300 \times 150 \mathrm{~mm}$ nylon bag with $1 \mathrm{~mm}^{2}$ mesh size. A total of 90 litter bags were prepared in the Nutrient Dynamics Laboratory, Khulna University, for each species in each season and 80 litter bags were placed randomly in the cropland and the remaining 10 bags were brought back to the laboratory for calculating oven-dry weights by drying at $80^{\circ} \mathrm{C}$ to constant weight. The litter bags were placed on December 1, 2012 for dry season and June 1, 2013 for wet season in the cropland.

2.4. Sample Collection and Processing. Ten bags were collected for each species at every 10-day interval for the initial 30 days and subsequently at 60-, 90-, 120-, 150-, and 180day interval for the remaining periods. The collected leaf litter samples were gently washed and all sediments and dirt particles were then removed by using a soft brush with running tap water followed by final rinsing in distilled water. Each sample was then oven-dried at $80^{\circ} \mathrm{C}$ to constant weight in the said laboratory.
2.5. Mass Loss and Decay Constant. The loss in dry mass of leaf samples was calculated from the initial converted ovendry mass and remaining mass. The rate of decomposition was calculated from the percentage of mass loss divided by respective days of sample collection. Decay constants for leaf litter were calculated using the negative exponential decay model as follows:

$$
\frac{X}{X_{0}}=\exp ^{(-k t)} \text { [29] }
$$

where $X$ is the weight remaining at time $t, X_{0}$ the initial weight, exp is the base of natural logarithm, $k$ is the decay rate coefficient, and $t$ is the time of placement in year. Halflife of each species was calculated using the equation Half-life $\left(t_{50}\right)=\ln 2 / \mathrm{K}[29]$.

2.6. Nutrients Concentration in Leaf Litter. The oven-dried leaf samples of individual species were ground and processed using acid digestion [30]. The digested sample extracts were processed according to $[31,32]$ to determine $\mathrm{N}$ and $\mathrm{P}$ concentrations using a UV-Visible recording spectrophotometer (U-2910, HITACHI, Japan) and K concentrations in sample extracts were determined by flame photometry (PFP7, Jenway LTD, England) in the said laboratory. The amount of nutrient released from leaf litters was calculated as differences between initial and final absolute mass also expressed as percentage of initial amount.

2.7. Statistical Analysis. The rate of mass loss and nutrients concentration $(\mathrm{N}, \mathrm{P}$, and $\mathrm{K}$ ) in leaf litter of different tree species at different collection time intervals and also with the tree species were compared by ANOVA analysis followed by Duncan multiple range test using SAS 6.12 statistical software. A $P$ value of $<0.05$ was used for significance. The relationship among the rate of leaf litter decomposition and site factors (monthly rainfall and temperature) was evaluated by correlation analysis using SAS 6.12 statistical software. Furthermore, the relationship among mass loss, nutrient concentrations ( $\mathrm{N}, \mathrm{P}$, and $\mathrm{K})$, and time was evaluated by regression analysis using SAS 6.12 statistical software. The differences between mass loss, N, P, and $\mathrm{K}$ concentrations in dry season and wet season were evaluated by unpaired $t$-test using SPSS (17) statistical software.

\section{Results}

3.1. Mass Loss. The mass loss due to microbial decomposition was significantly different $(P<0.05)$ at different sampling times during the dry and wet season for all the studied tree species (Table 1). The comparatively highest (49\% and 57\%) mass losses were observed for A. heterophyllus and the lowest (25\% and 25\%) were for L. chinensis during 180 days in the dry and wet seasons, respectively (Figure 1). The initial rate of decomposition (10 days) was the highest (0.75\% per day) for $Z$. jujuba and the lowest ( $0.50 \%$ per day) was for L. chinensis while the final rate of decomposition (180 days) was the highest $(0.27 \%$ per day) for A. heterophyllus and the lowest (0.14\% per day) was for L. chinensis in dry season (Figure 2). 
TABLE 1: Significant test of mass loss of leaf litter of the selected cropland agroforest horticultural tree species among dry and wet season.

\begin{tabular}{lccccccccc}
\hline Name of species & 00 days & 10 days & 20 days & 30 days & 60 days & 90 days & 120 days & 150 days & 180 days \\
\hline \multirow{2}{*}{ A. heterophyllus } & 0.11 & 7.24 & 11.55 & 9.47 & 8.66 & 6.16 & 7.18 & 2.53 & 1.78 \\
& $P<0.91$ & $P<0.001$ & $P<0.001$ & $P<0.001$ & $P<0.001$ & $P<0.001$ & $P<0.001$ & $P<0.010$ & $P<0.046$ \\
\hline \multirow{2}{*}{ M. indica } & 0.23 & 8.51 & 4.26 & 8.08 & 8.19 & 11.52 & 10.03 & 3.05 & 2.5 \\
& $P<0.87$ & $P<0.001$ & $P<0.001$ & $P<0.001$ & $P<0.001$ & $P<0.001$ & $P<0.001$ & $P<0.003$ & $P<0.010$ \\
\hline \multirow{2}{*}{ Z. jujuba } & 0.16 & 14.07 & 16.14 & 19.96 & 16.84 & 15.47 & 22.21 & 7.60 & 4.69 \\
& $P<0.89$ & $P<0.001$ & $P<0.001$ & $P<0.001$ & $P<0.001$ & $P<0.001$ & $P<0.001$ & $P<0.001$ & $P<0.001$ \\
\hline \multirow{2}{*}{ L. chinensis } & 0.05 & 2.70 & 3.75 & 3.34 & 3.80 & 8.02 & 5.46 & 3.51 & 1.70 \\
& $P<0.96$ & $P<0.007$ & $P<0.001$ & $P<0.002$ & $P<0.001$ & $P<0.001$ & $P<0.001$ & $P<0.001$ & $P<0.054$ \\
\hline
\end{tabular}

TABLE 2: Average decay constant and half-life $\left(t_{50}\right)$ of leaf litter of selected cropland agroforest horticultural tree species during microbial decomposition in dry and wet season.

\begin{tabular}{|c|c|c|c|c|}
\hline \multirow{2}{*}{ Name of species } & \multicolumn{2}{|c|}{ Dry season } & \multicolumn{2}{|c|}{ Wet season } \\
\hline & Average decay constant (K) & $t_{50}$ (Days) & Average decay constant $(\mathrm{K})$ & $t_{50}$ (days) \\
\hline A. heterophyllus & 2.14 & 118 & 2.34 & 108 \\
\hline Z. jujuba & 2.03 & 125 & 2.24 & 113 \\
\hline M. indica & 1.44 & 176 & 1.61 & 157 \\
\hline L. chinensis & 0.88 & 289 & 0.94 & 270 \\
\hline
\end{tabular}

TABLE 3: Relationship among rainfall and temperature with mass loss of leaf litter of selected cropland agroforest horticultural tree species (dry and wet season).

\begin{tabular}{|c|c|c|c|c|}
\hline \multirow[t]{2}{*}{ Name of species } & \multicolumn{2}{|c|}{$\begin{array}{l}\text { Rainfall versus mass loss relationship } \\
\text { (correlation coefficient and } P \text { value) }\end{array}$} & \multicolumn{2}{|c|}{$\begin{array}{l}\text { Temperature versus mass loss } \\
\text { relationship } \\
\text { (correlation coefficient and } P \text { value) }\end{array}$} \\
\hline & Dry season & Wet season & Dry season & Wet season \\
\hline A. heterophyllus & $r=0.12, P=0.82$ & $r=0.47, P=0.35$ & $r=0.15, P=0.78$ & $r=0.86, P=0.03$ \\
\hline M. indica & $r=0.31, P=0.55$ & $r=0.38, P=0.45$ & $r=0.31, P=0.55$ & $r=0.88, P=0.02$ \\
\hline Z. jujuba & $r=0.13, P=0.80$ & $r=0.44, P=0.38$ & $r=0.22, P=0.68$ & $r=0.87, P=0.02$ \\
\hline L. chinensis & $r=0.16, P=0.76$ & $r=0.40, P=0.43$ & $r=0.24, P=0.65$ & $r=0.87, P=0.02$ \\
\hline
\end{tabular}

TABLE 4: Significant test of N concentration of leaf litter of the selected cropland agroforest horticultural tree species among dry and wet season.

\begin{tabular}{lccccccccc}
\hline Name of species & 00 days & 10 days & 20 days & 30 days & 60 days & 90 days & 120 days & 150 days & 180 days \\
\hline \multirow{2}{*}{ A. heterophyllus } & 0.34 & 1.55 & 1.47 & 4.19 & 3.81 & 1.63 & 2.20 & 4.64 & 4.11 \\
& $P<0.38$ & $P<0.99$ & $P<0.11$ & $P<0.007$ & $P<0.009$ & $P<0.09$ & $P<0.05$ & $P<0.005$ & $P<0.007$ \\
\hline \multirow{2}{*}{ M. indica } & 0.59 & 4.19 & 5.44 & 6.97 & 9.78 & 14.91 & 15.28 & 9.27 & 8.98 \\
& $P<0.69$ & $P<0.007$ & $P<0.003$ & $P<0.001$ & $P<0.001$ & $P<0.001$ & $P<0.001$ & $P<0.001$ & $P<0.001$ \\
\hline \multirow{2}{*}{ Z. jujuba } & 0.24 & 3.04 & 2.83 & 6.15 & 2.61 & 7.52 & 16.21 & 14.51 & 8.37 \\
& $P<0.29$ & $P<0.019$ & $P<0.024$ & $P<0.002$ & $P<0.03$ & $P<0.001$ & $P<0.001$ & $P<0.001$ & $P<0.001$ \\
\hline \multirow{2}{*}{ L. chinensis } & 0.76 & 4.53 & 3.37 & 5.03 & 5.05 & 5.32 & 3.89 & 2.61 & 0.54 \\
& $P<0.84$ & $P<0.005$ & $P<0.014$ & $P<0.004$ & $P<0.004$ & $P<0.003$ & $P<0.009$ & $P<0.030$ & $P<0.31$ \\
\hline
\end{tabular}

TABle 5: Significant test of $\mathrm{P}$ concentration of leaf litter of the selected cropland agroforest horticultural tree species among dry and wet season.

\begin{tabular}{lccccccccc}
\hline Name of species & 00 days & 10 days & 20 days & 30 days & 60 days & 90 days & 120 days & 150 days & 180 days \\
\hline \multirow{2}{*}{ A. heterophyllus } & 1.56 & 0.57 & 2.005 & 0.300 & 0.30 & 3.17 & 0.80 & 0.184 & 2.145 \\
& $P<0.097$ & $P<0.30$ & $P<0.058$ & $P<0.389$ & $P<0.390$ & $P<0.017$ & $P<0.234$ & $P<0.432$ & $P<0.049$ \\
\hline \multirow{2}{*}{ M. indica } & 0.70 & 5.83 & 0.84 & 3.002 & 0.64 & 0.70 & 5.50 & 7.84 & 3.69 \\
& $P<0.26$ & $P<0.002$ & $P<0.225$ & $P<0.020$ & $P<0.28$ & $P<0.26$ & $P<0.003$ & $P<0.001$ & $P<0.010$ \\
\hline \multirow{2}{*}{ Z. jujuba } & 0.36 & 3.73 & 1.49 & 0.40 & 0.54 & 0.60 & 1.02 & 0.55 & 1.92 \\
& $P<0.37$ & $P<0.010$ & $P<0.11$ & $P<0.36$ & $P<0.31$ & $P<0.29$ & $P<0.182$ & $P<0.31$ & $P<0.061$ \\
\hline \multirow{2}{*}{ L. chinensis } & 0.45 & 1.56 & 0.09 & 0.60 & 0.82 & 3.04 & 2.43 & 0.83 & 5.04 \\
& $P<0.34$ & $P<0.097$ & $P<0.47$ & $P<0.29$ & $P<0.23$ & $P<0.02$ & $P<0.04$ & $P<0.22$ & $P<0.004$ \\
\hline
\end{tabular}


TABLE 6: Significant test of K concentration of leaf litter of the selected cropland agroforest horticultural tree species among dry and wet season.

\begin{tabular}{lccccccccc}
\hline Name of species & 00 days & 10 days & 20 days & 30 days & 60 days & 90 days & 120 days & 150 days & 180 days \\
\hline \multirow{2}{*}{ A. heterophyllus } & 0.67 & 12.97 & 10.02 & 52.22 & 17.37 & 1.86 & 4.98 & 14.89 & 11.58 \\
& $P<0.78$ & $P<0.001$ & $P<0.001$ & $P<0.001$ & $P<0.001$ & $P<0.068$ & $P<0.004$ & $P<0.001$ & $P<0.001$ \\
\hline \multirow{2}{*}{ M. indica } & 0.35 & 37.41 & 4.89 & 7.49 & 0.155 & 5.73 & 6.52 & 4.83 \\
& $P<0.44$ & $P<0.001$ & $P<0.004$ & $P<0.001$ & $P<0.442$ & $P<0.002$ & $P<0.001$ & $P<0.004$ & $P<0.001$ \\
\hline \multirow{2}{*}{ Z. jujuba } & 0.77 & 18.11 & 16.01 & 8.55 & 57.33 & 3.73 & 0.89 & 10.72 & 17.78 \\
& $P<0.82$ & $P<0.001$ & $P<0.001$ & $P<0.001$ & $P<0.001$ & $P<0.010$ & $P<0.21$ & $P<0.001$ & $P<0.001$ \\
\hline \multirow{2}{*}{ L. chinensis } & 0.64 & 2.04 & 11.38 & 10.03 & 5.21 & 3.03 & 2.73 & 0.44 & 6.12 \\
& $P<0.91$ & $P<0.06$ & $P<0.001$ & $P<0.001$ & $P<0.003$ & $P<0.02$ & $P<0.03$ & $P<0.34$ & $P<0.001$ \\
\hline
\end{tabular}

TABLE 7: Nutrients added through microbial decomposition of leaf litter of cropland agroforest horticultural tree species in dry and wet season.

\begin{tabular}{|c|c|c|c|c|c|c|}
\hline \multirow{2}{*}{ Species } & \multicolumn{2}{|c|}{$\mathrm{N}$ concentration $(\mathrm{mg} / \mathrm{g})$} & \multicolumn{2}{|c|}{$\mathrm{P}$ concentration $(\mathrm{mg} / \mathrm{g})$} & \multicolumn{2}{|c|}{ K concentration $(\mathrm{mg} / \mathrm{g})$} \\
\hline & Dry season & Wet season & Dry season & Wet season & Dry season & Wet season \\
\hline M. indica & 9.06 & 13.93 & 3.74 & 1.00 & 27.82 & 25.42 \\
\hline A. heterophyllus & 17.22 & 8.22 & 11.47 & 18.95 & 48.39 & 45.63 \\
\hline L. chinensis & 12.20 & 8.48 & 3.16 & 3.50 & 36.96 & 31.26 \\
\hline Z. jujuba & 21.81 & 25.11 & 14.31 & 15.54 & 53.95 & 55.34 \\
\hline
\end{tabular}

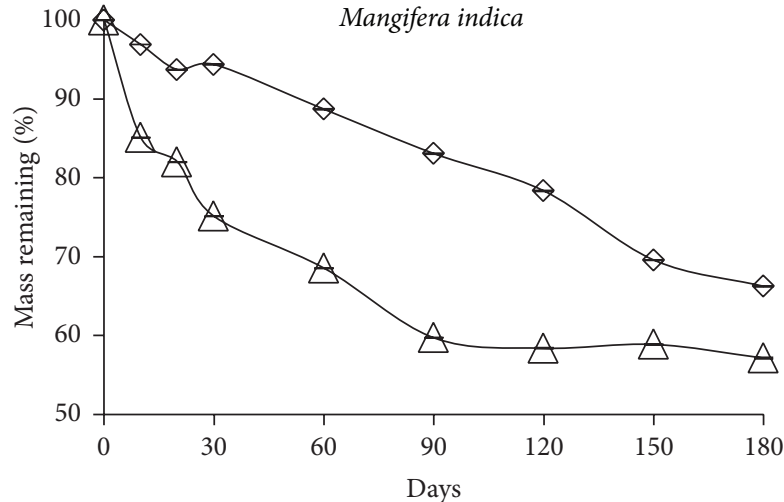

$\diamond$ Dry season

$\triangle$ Wet season

(a)

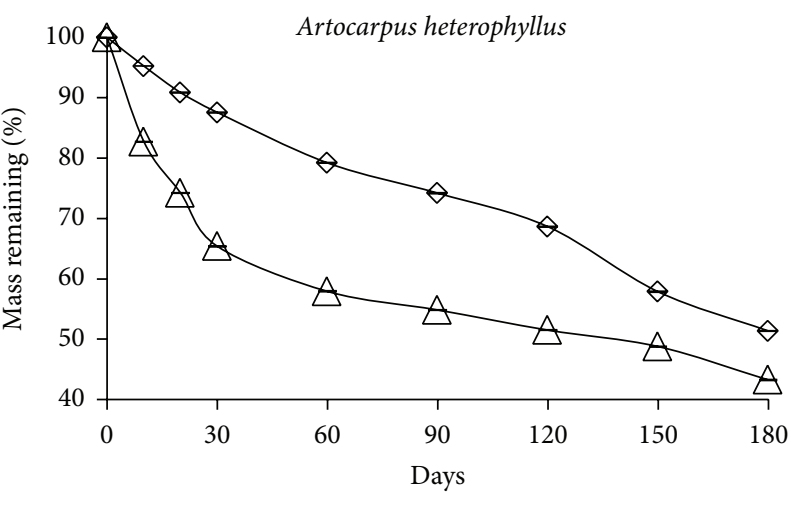

$\diamond$ Dry season

$\triangle$ Wet season

(c)

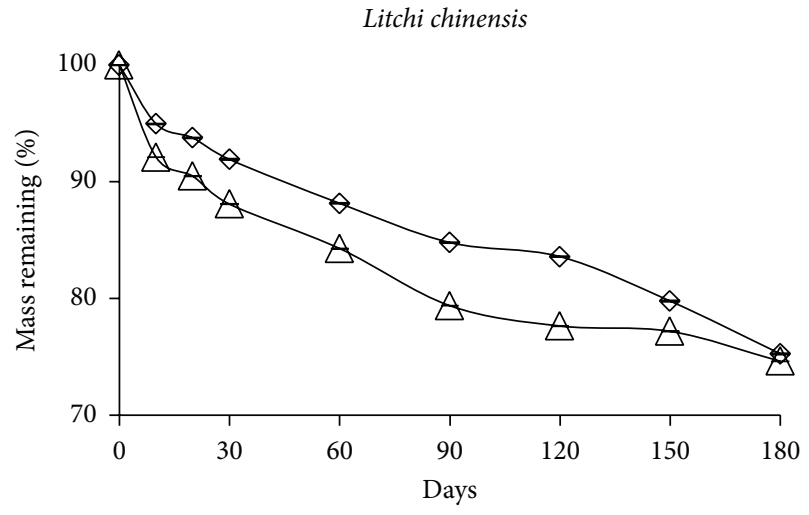

$\diamond$ Dry season

$\triangle$ Wet season

(b)

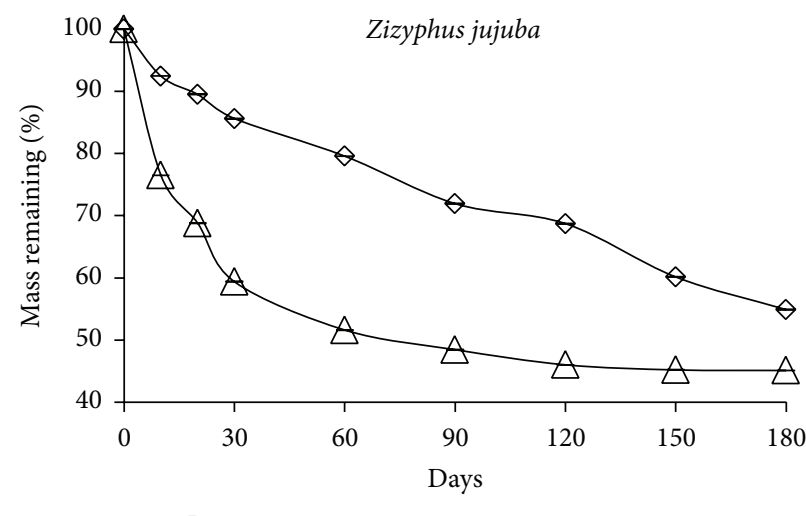

$\diamond$ Dry season

$\triangle$ Wet season

FIGURE 1: Decomposition of leaf litter of four tree species used in agroforestry during the dry and wet seasons over 180-day periods. 


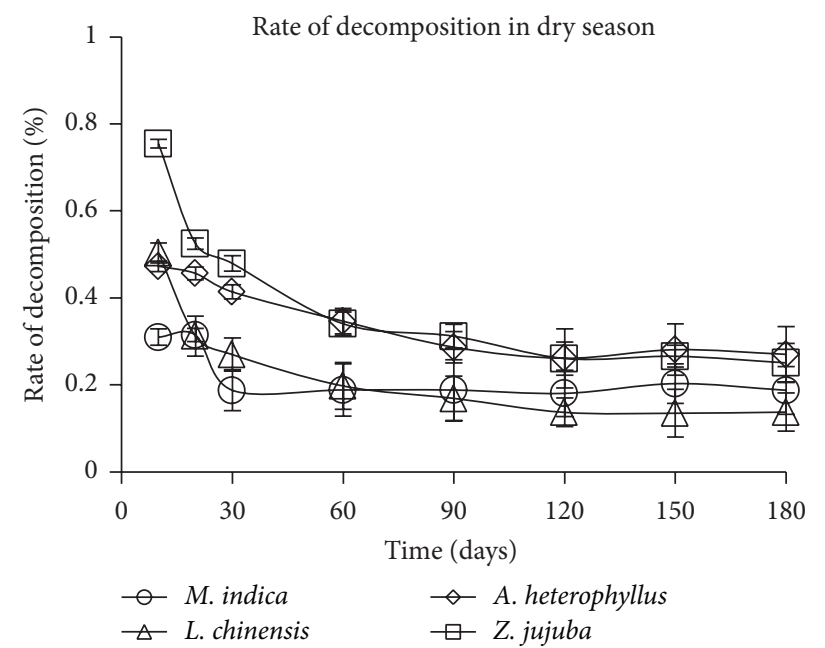

(a)

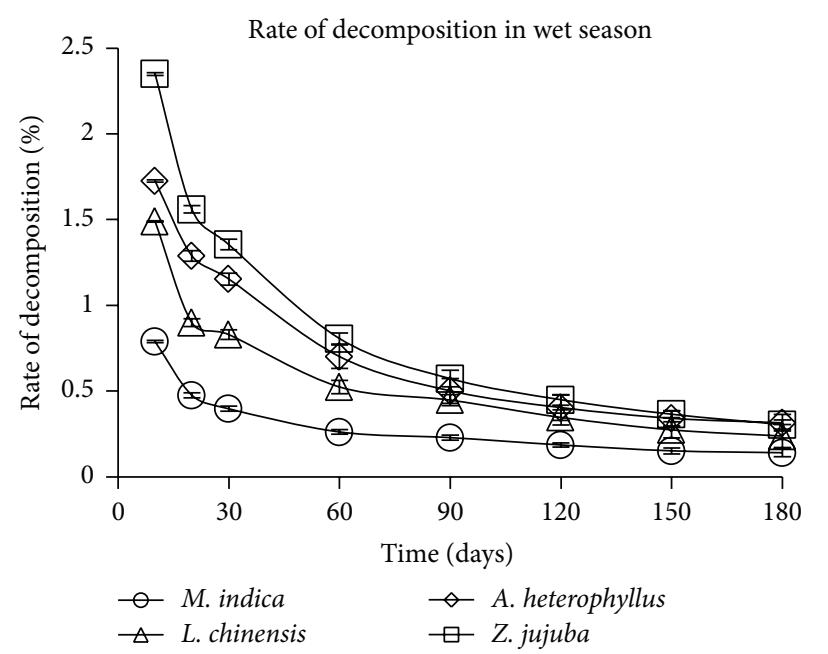

(b)

FIGURE 2: Rate of decomposition of leaf litter of four tree species used in agroforestry during the dry and wet seasons over 180-day periods.

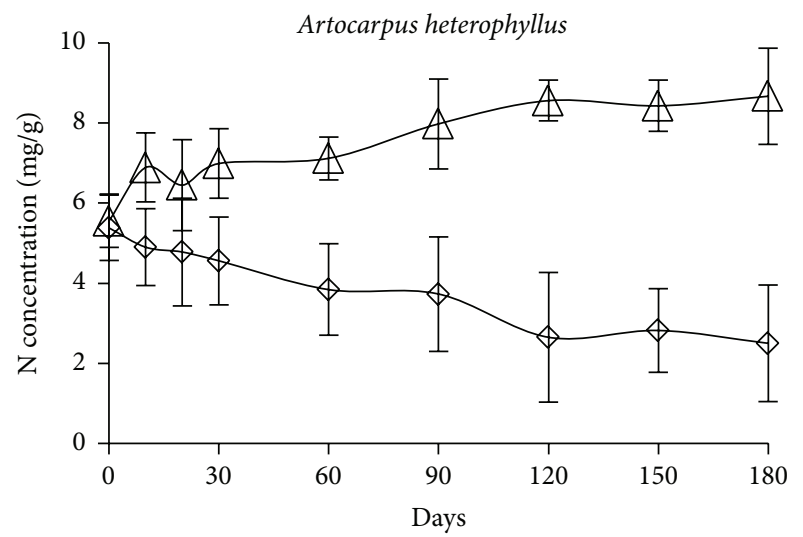

$\diamond$ Dry season

$\triangle$ Wet season

(a)

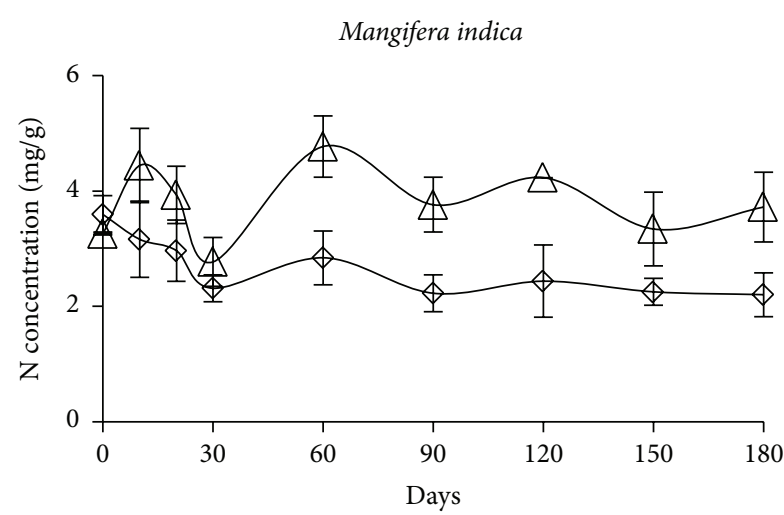

$\diamond$ Dry season

$\triangle$ Wet season

(c)
Litchi chinensis

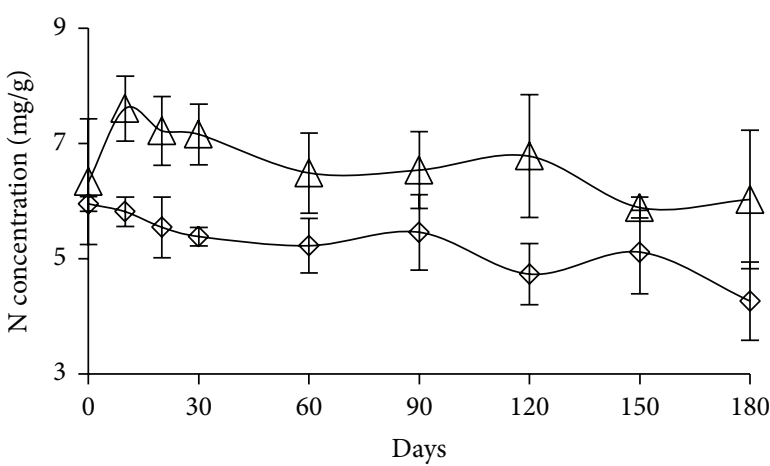

$\diamond$ Dry season

$\triangle$ Wet season

(b)

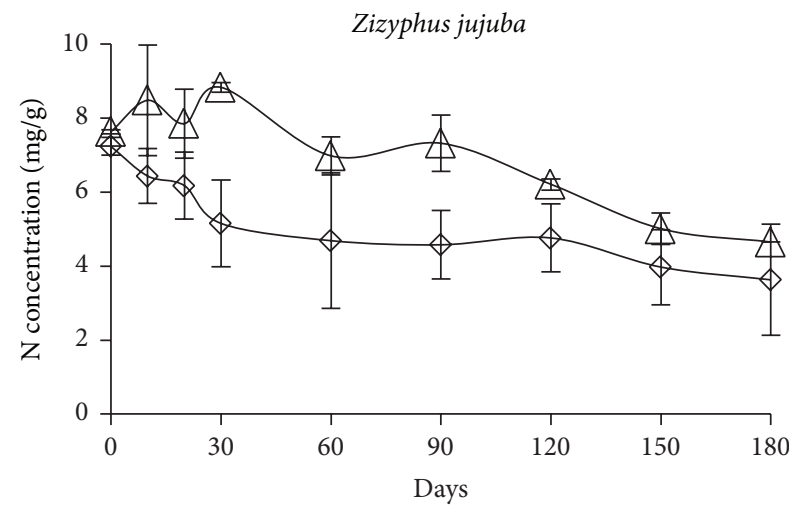

$\diamond$ Dry season

$\triangle$ Wet season

(d)

FIGURE 3: N concentration (mg/g) of leaf litter of four tree species used in agroforestry during the dry and wet seasons over 180-day periods due to microbial decomposition. 


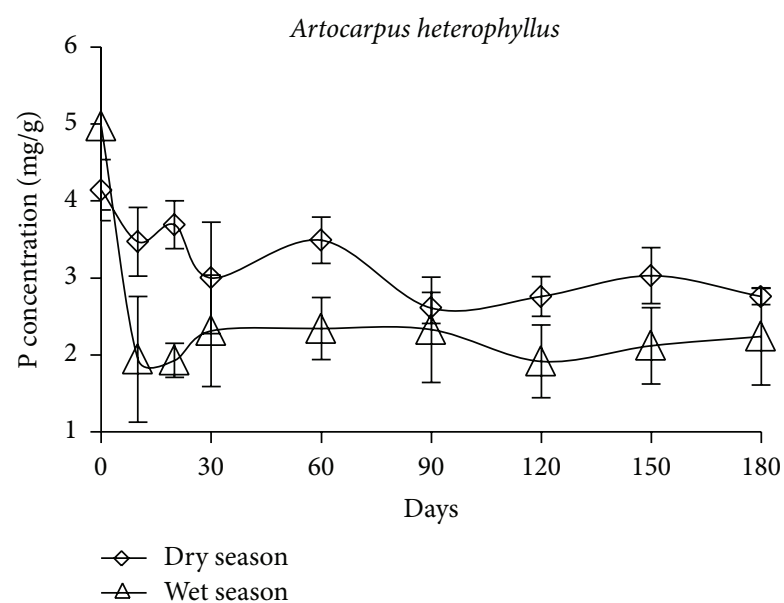

(a)

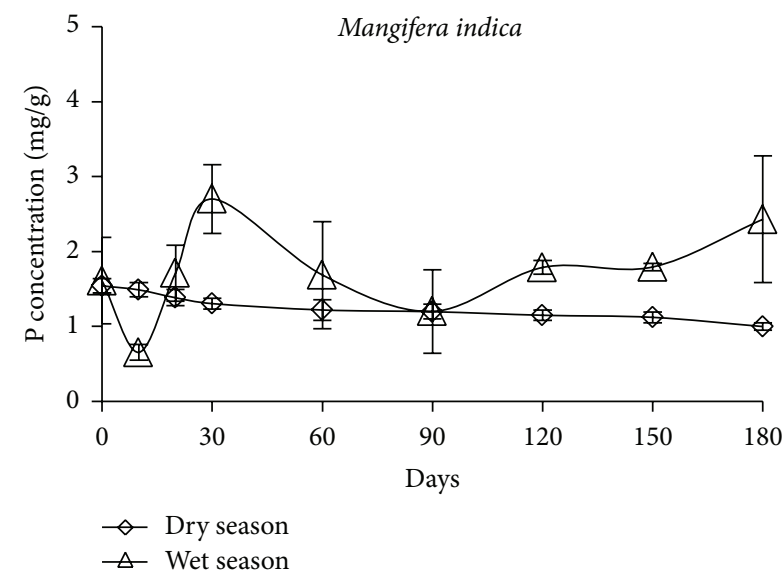

(c)

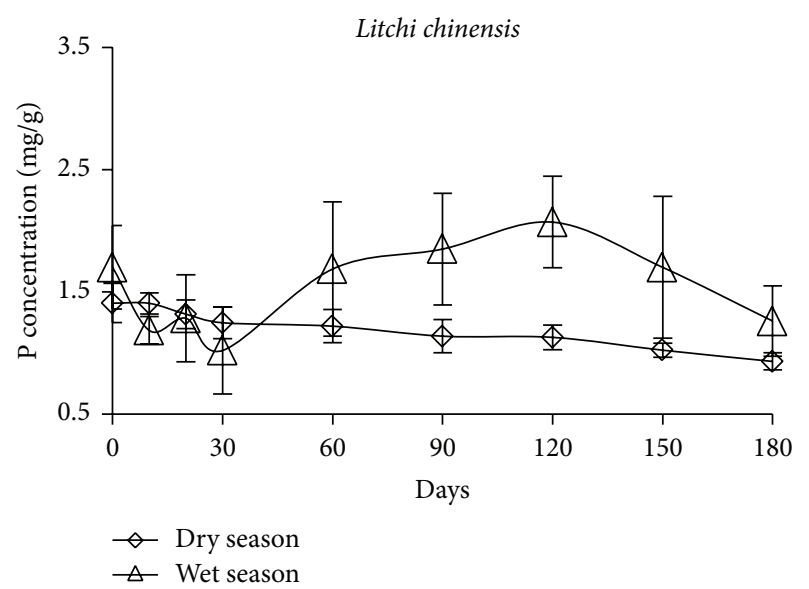

(b)

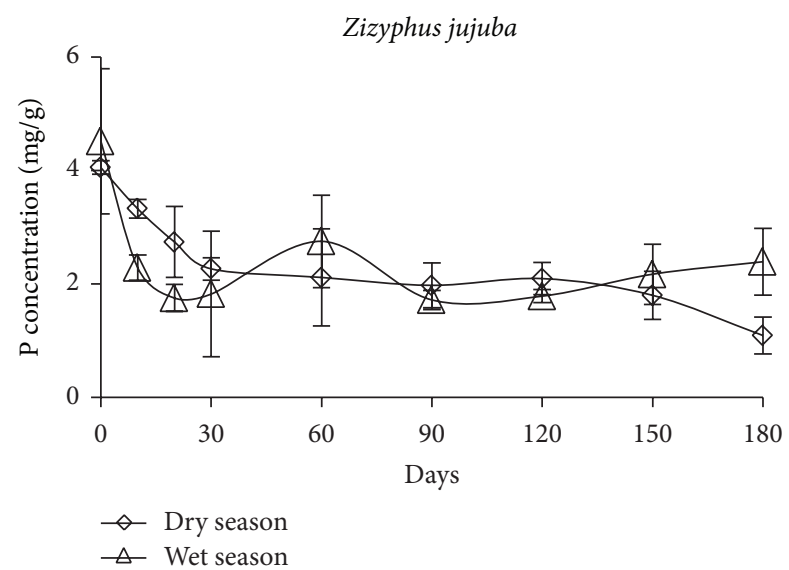

(d)

Figure 4: P concentration (mg/g) of leaf litter of four tree species used in agroforestry during the dry and wet seasons over 180-day periods due to microbial decomposition.

The initial rate of decomposition (10 days) was the highest (2.35\% per day) for Z. jujuba and the lowest ( $0.79 \%$ per day) was for $L$. chinensis while the final rate of decomposition (180 days) was the highest $(0.32 \%$ per day) for A. heterophyllus and the lowest $(0.14 \%$ per day) was for $L$. chinensis in the wet season (Figure 2). The rate of decomposition of other agroforestry tree species of tropical region was found the highest (3.6\% per day) for M. azadirachta, followed by $A$. indica (2.9\% per day) and D. sissoo (2.4\% per day) [6]. The decay constant $(\mathrm{k})$ was the highest for A. heterophyllus (2.14 and 2.34) followed by $Z$. jujuba (2.03 and 2.24) and $M$. indica (1.44 and 1.61) and the lowest was for L. chinensis (0.88 and 0.94$)$ in dry and wet seasons, respectively (Table 2 ). Conversely highest half-life was detected for $L$. chinensis (289 days and 270 days) followed by $M$. indica (176 days and 157 days) and $Z$. jujuba (125 days and 113 days) and the lowest was for A. heterophyllus (118 days and 108 days) in dry and wet seasons, respectively (Table 2 ). The microbial decomposition rate of leaf litter of the studied tree species showed positive relationship with rainfall and temperature in both dry and wet seasons (Table 3 ).
3.2. Nutrients at Different Stages of Microbial Decomposition Process. The nutrients concentration was found to decrease gradually at the end of the experiment (180 days) in dry season (Figures 3, 4, and 5). Conversely, nutrients concentration decreased in the initial stage but increased at the end of experiment in wet season (Figures 3, 4, and 5). A rapid decrease in $\mathrm{P}$ concentration was observed at the end of first month and a rapid decrease in $\mathrm{K}$ concentration occurred in the first 10 days while $\mathrm{N}$ concentrations increased gradually during the leaf litter decomposition in the wet season (Figures 3 , 4, and 5). The concentrations of $\mathrm{N}, \mathrm{P}$, and $\mathrm{K}$ showed significant $(P<0.05)$ differences between dry and wet seasons (Tables 4, 5 and 6 ) but the differences among initial concentrations were not significant $(P<0.05)$. Leaf litter showed a similar pattern $(\mathrm{K}>\mathrm{N}>\mathrm{P})$ of initial nutrient concentration in all the studied species (Figures 3, 4, and 5). The highest concentrations of $\mathrm{N}(22$ and $25 \mathrm{mg} / \mathrm{g}$ ) and $\mathrm{K}$ ( 54 and $55 \mathrm{mg} / \mathrm{g}$ ) were added to the soil from the leaf litter of $Z$. jujuba, whereas the highest concentration of $\mathrm{P}(12$ and $19 \mathrm{mg} / \mathrm{g}$ ) was added to the soil from the leaf litter of $A$. heterophyllus in dry and wet seasons, respectively. The lowest 


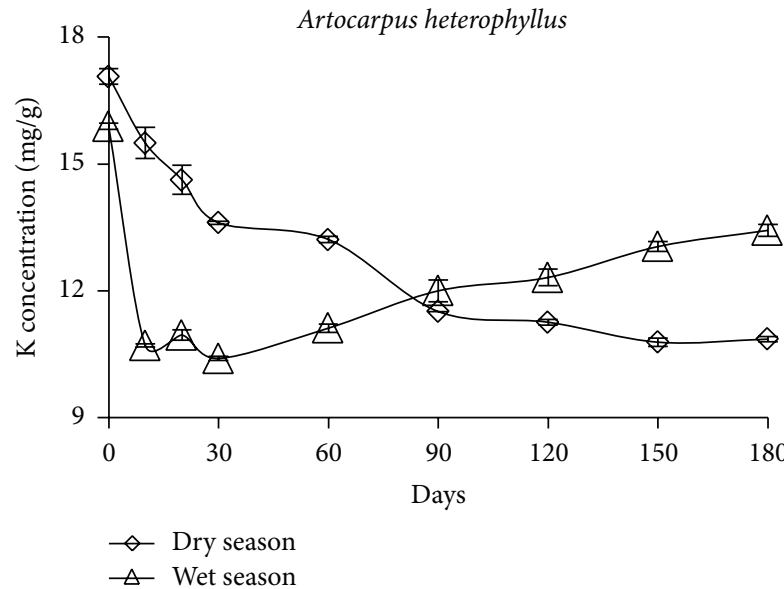

(a)

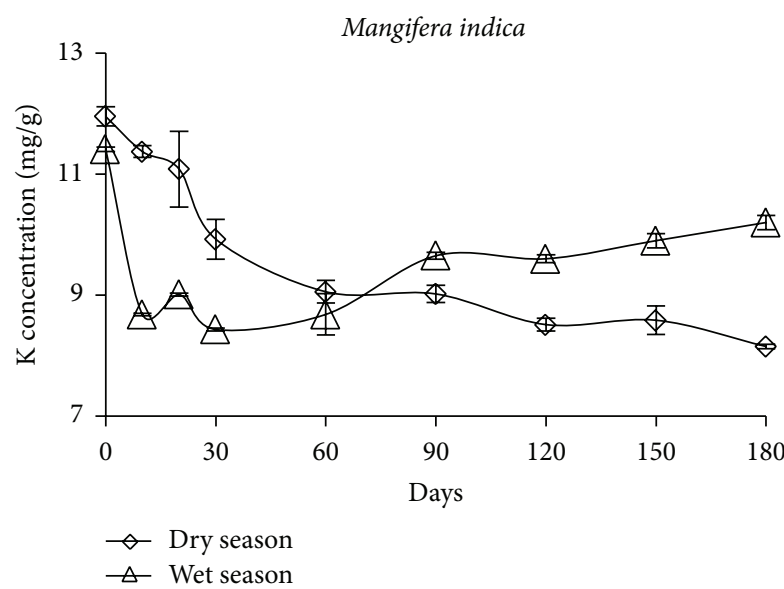

(c)

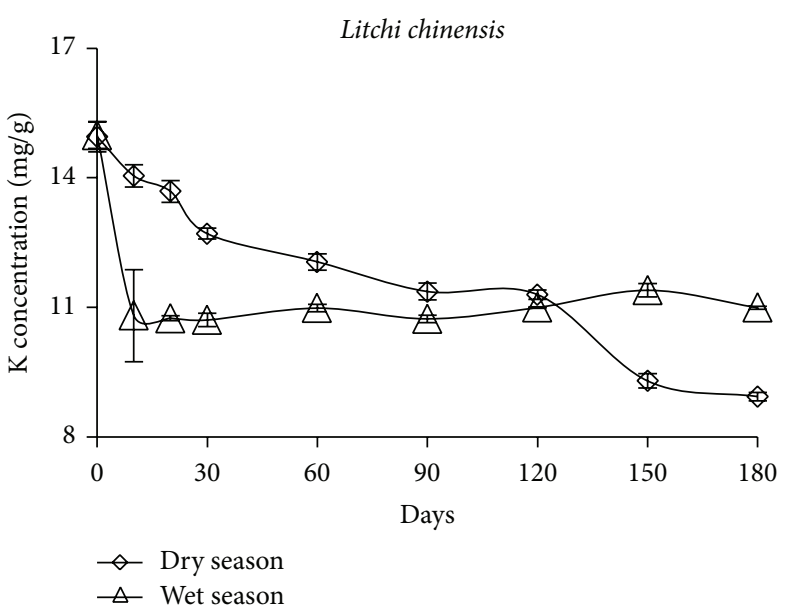

(b)

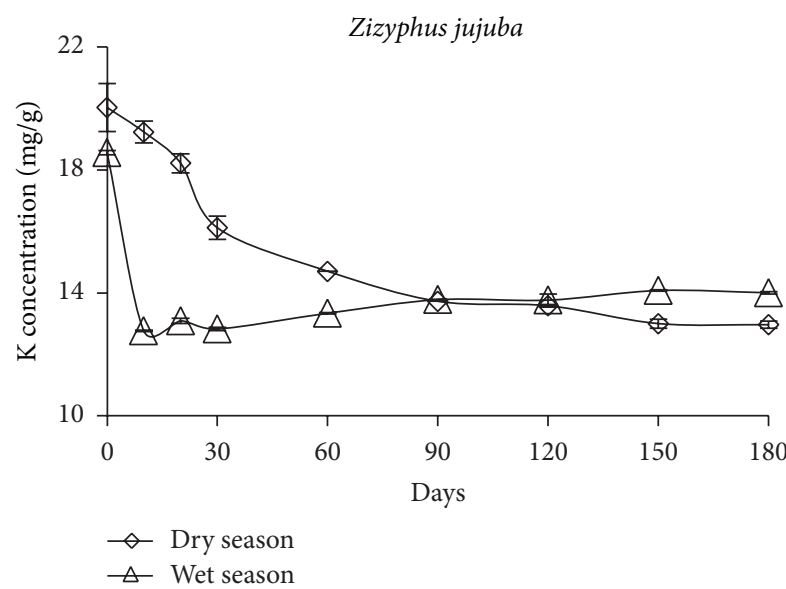

(d)

FIGURE 5: K concentration (mg/g) of leaf litter of four tree species used in agroforestry during the dry and wet seasons over 180-day periods due to microbial decomposition.

concentration of $\mathrm{N}$ ( 9 and $14 \mathrm{mg} / \mathrm{g}$ ), P (4 and $1 \mathrm{mg} / \mathrm{g}$ ), and $\mathrm{K}$ ( 28 and $25 \mathrm{mg} / \mathrm{g}$ ) was added to the soil from the leaf litter of M. indica in dry and wet seasons, respectively (Table 7).

\section{Discussion}

4.1. Mass Loss. The mass loss pattern and rate of decomposition showed significant $(P<0.05)$ differences among the studied tree species (Figures 1 and 2) which may be due to the litter quality, the presence of varying amounts of water soluble phenolic compounds, flavonoids, tannin, physical and chemical properties of leaf litter, and the presence of thick waxy cuticle $[18,33,34]$. Mass of leaf litter decreased gradually during the experiment in dry and wet season due to decomposition $[6,20]$. Higher rate of decomposition of leaf litter was found during the first 30 days, followed by a gradual mass loss for the subsequent 150 days (Figure 2) which indicates two stages, that is, initial stage and advanced stage $[26,35]$. In the initial stage, relatively larger decrease in mass was observed due to leaching of readily soluble substances and nonlignified carbohydrates [36-38]. While in the advanced stage, the further decrease in mass loss may be attributed to the release of higher percentage of recalcitrant fractions like cellulose, lignin, and tannin of leaf litter [39]. The shorter half-life found for wet season and higher halflife found for dry season (Table 2) may be attributed to microclimatic variations $[6,40]$. The decay constant range, $k$ $=2.14-0.88$ in dry season and $k=2.34-0.94$ in wet season, was found for this study while $k=3.46-2.35$ was found for three tropical agroforestry tree species (Mangifera indica, Artocarpus heterophyllus, and Anacardium occidentale) as reported by Isaac and Nair but higher range of decay constant, $k=6.67-3.91$, was found for the other three tropical agroforestry tree species (Melia azadirachta, Azadirachta indica, and Dalbergia sissoo) as reported by Isaac and Nair [41] and Hossain et al. [6]. Alvarez et al. [42] reported that $k$ value is often greater than 1.0 for tropical forests indicating that leaf litter turnover occurred in a year or less than a year. The higher range of decay constant was found in wet season than dry season because of site factors, that is, rainfall also reported by Semwal et al. [26] and Isaac and Nair [41]. The decay constant varied from species to species (Table 2) 
also reported by Hossain et al. [6] and Mahmood et al. [20] and varied within a species for the differences in the length of decomposition period and different land use types [17]. The highest rate of leaf litter decomposition of $Z$. jujuba could be an indicator of higher litter quality, compared to other studied tree species also reported by Hossain et al. [6].

\subsection{Nutrients at Different Stages of Microbial Decomposition} Process. The variation in nutrients (N, P, and $\mathrm{K}$ ) concentration in the leaf litter of the studied species at the initial stages of decomposition was found (Figures 3, 4, and 5) as the selected tree species were from different families having variation in chemical and biochemical properties of leaf litter [43-45]. Comparatively higher initial concentration of $\mathrm{N}$, $\mathrm{P}$, and $\mathrm{K}$ concentration in the leaf litter of $Z$. jujuba indicated that capabilities of this species to retranslocate these nutrients were lower during the senescence of leaves $[6,46,47]$. The faster decreasing of $\mathrm{K}$ concentration from leaf litter was observed as it is a nonstructural element and highly mobile to be the most leachable cation during the decomposition of litter [24, 48-50]. $\mathrm{N}$ is structurally bound with cell wall and leaf contained comparatively lower concentration of $\mathrm{P}[6,51,52]$. The initial rapid decrease of nutrients concentration (Figures 3, 4, and 5) observed may be due to the loss of the soluble forms of nutrients at the initial stages of decomposition [38] and a slower release of nutrients at the later stages of leaf litter decomposition governed by microbial oxidation of refractory components and physical and biological fragmentation [20, 49]. On the contrary, increased concentration of nutrients $(\mathrm{N}, \mathrm{P}$, and $\mathrm{K})$ at different stages of decomposition in wet season (Figures 3, 4, and 5) was attributed to microbial or nonmicrobial immobilization in the residual leaf litter while leaf litter acts as a surface for fungi or heterotrophic organisms $[6,20,53]$.

\section{Conclusions}

A considerable amount of organic matter and nutrients added to the soil through the process of leaf litter decomposition and a portion of these organic matter and nutrients would be reused by the plants. More organic matter and nutrients can be added to the soil through the process of leaf litter decomposition during wet season because of higher rate of decomposition in wet season than dry season. The added nutrients may contribute to the sustainability of soil fertility, which is becoming an important phenomenon for agroforestry practices. Among the considered tree species, $Z$. jujuba was found to be the best followed by A. heterophyllus, L. chinensis, and M. indica in terms of N, P, and K return.

\section{Conflict of Interests}

The authors declare that there is no conflict of interests regarding the publication of this paper.

\section{Acknowledgments}

The authors wish to thank Bangladesh Academy of Sciences (BAS) for the financial support through BAS-USDA
Programme in Agricultural and Life Science Innovative Research Fund. The authors are also thankful to Forestry and Wood Technology Discipline of Khulna University, Bangladesh, for the logistic supports throughout the study period.

\section{References}

[1] Interagency Agroforestry Team, "Agroforestry: a unique land management system of Working Trees," Tech. Rep., USDA, Washington, DC, USA, 2010.

[2] M. F. U. Ahmed, S. M. L. Rahman, A. S. M. M. Ahmed, and B. Quebedeaux, "Agroforestry as it pertains to vegetable production in Bangladesh," Journal of Agronomy, vol. 3, pp. 282290, 2004.

[3] T. Ya, Role of Tree in Croplands: In Forest and Forest Plants, vol. 3, 2002, http://www.eolss.net/ebooklib/.

[4] M. Zashimuddin, "Community forestry for poverty reduction in Bangladesh," in Proceedings of the Regional Workshop on Forest for Poverty Reduction: Can Community Forestry Make Money? H. C. Sim, S. Appanah, and W. M. Lu, Eds., Beijing, China, September 2004.

[5] A. P. Dwivedi, Agroforestry Principles and Practices, IBH Publishing, New Delhi, India, 1992.

[6] M. Hossain, M. R. H. Siddique, M. S. Rahman, M. Z. Hossain, and M. M. Hasan, "Nutrient dynamics associated with leaf litter decomposition of three agroforestry tree species (Azadirachta indica, Dalbergia sissoo, and Melia azedarach) of Bangladesh," Journal of Forestry Research, vol. 22, no. 4, pp. 577-582, 2011.

[7] G. L. Smiley and J. Kroschel, "Yield development and nutrient dynamics in cocoa-gliricidia agroforests of Central Sulawesi, Indonesia," Agroforestry Systems, vol. 78, no. 2, pp. 97-114, 2010.

[8] M. F. U. Ahmed, "Agroforestry in Bangladesh with special reference to northern Bangladesh," in Proceedings of the National Workshop on Agroforestry Research: Development of Agroforestry Research in Bangladesh, M. F. Haq, M. K. Hasan, S. M. Asaduzzaman, and M. Y. Ali, Eds., pp. 1-10, Gazipur, Bangladesh, September 2001.

[9] S. A. Rahman, F. D. Paras, S. R. Khan et al., "Initiatives of tropical agroforestry to sustainable agriculture: a case study of Capasia Village, Northern Bangladesh," Journal of Horticulture and Forestry, vol. 3, pp. 115-121, 2011.

[10] M. Hasanuzzaman, H. Mahmood, and M. Saroar, "Floristic composition and management of cropland agroforest in Southwestern Bangladesh," Journal of Forestry Research, 2014.

[11] M. Hasanuzzaman, H. Mahmood, S. H. Lemon, and M. N. Islam, "Nutrients ( $\mathrm{P}, \mathrm{K}$ and $\mathrm{Na}$ ) leaching from leaf litter of Dalbergia Sissoo (Roxb.)," Pakistan Journal of Forestry, vol. 56, no. 1, pp. 22-29, 2006.

[12] M. Hasanuzzaman, H. Mahmood, S. H. Limon, and M. R. H. Siddique, "Effect of Shrimp pond sludge on seedling growth of Mahogany (Swietenia macrophylla)," Khulna University Studies, vol. 12, pp. 149-155, 2013.

[13] H. Mahmood and O. Saberi, "Degradation rate of leaf litter of Bruguiera parviflora of mangrove forest of Kuala Selangor, Malaysia," Indian Journal of Forestry, vol. 28, pp. 144-149, 2005.

[14] M. Hasanuzzaman and H. Mahmood, "Litter production and nutrient return through leaf litter of selected cropland agroforest tree species in Southwestern Bangladesh," Agriculture \& Forestry, vol. 60, pp. 221-233, 2014. 
[15] H. Mahmood and A. K. F. Hoque, "Litter production and decomposition in mangrove-a review," Indian Journal of Forestry, vol. 3, pp. 227-238, 2008.

[16] A. Ngoran, N. Zakra, K. Ballo et al., "Litter decomposition of Acacia auriculiformis Cunn. Ex Benth. and Acacia mangium Willd. under coconut trees on quaternary sandy soils in Ivory Coast," Biology and Fertility of Soils, vol. 43, no. 1, pp. 102-106, 2006.

[17] S. Triadiati, E. Tjitrosemito, G. Sundarsono, I. Qayim, and C. Leuschner, "Litterfall production and leaf-litter decomposition at natural forest and Cacao agroforestry in Central Sulawesi, Indonesia," Asian Journal of Biological Sciences, vol. 4, pp. 221234, 2011.

[18] F. C. Mason, Decomposition, The Institute of Biology's Studies in Biology, Edward Arnold, London, UK, 1977.

[19] S. Park and C. Kang-Hyun, "Nutrient leaching from leaf litter of emergent macrophyte (Zizania latifolia) and the effects of water temperature on the leaching process," Korean Journal of Biological Sciences, vol. 7, pp. 289-294, 2003.

[20] H. Mahmood, M. R. H. Siddique, S. M. R. Abdullah et al., "Nutrient dynamics associated with leaching and microbial decomposition of four abundant mangrove species leaf litter of the Sundarbans, Bangladesh," Wetlands, vol. 34, no. 3, pp. 439448, 2014.

[21] I. Valiela, J. M. Teal, S. D. Allen, R. Van Etten, D. Goehringer, and S. Volkmann, "Decomposition in salt marsh ecosystems: the phases and major factors affecting disappearance of aboveground organic matter," Journal of Experimental Marine Biology and Ecology, vol. 89, no. 1, pp. 29-54, 1985.

[22] M. Hasanuzzaman and H. Mahmood, "Nutrient leaching from leaf litter of cropland agroforest tree species of Bangladesh," Journal of Forest and Environmental Science, vol. 30, no. 2, pp. 208-217, 2014.

[23] J. Benton Jones Jr., Plant Nutrition Manual, CRC Press, New York, NY, USA, 1998.

[24] H. Marschner, Mineral Nutrition of Higher Plants, Academic Press, New York, NY, USA, 1995.

[25] M. Hasanuzzaman and H. Mahmood, "Nutrient return through leaf litter decomposition of common cropland agroforest tree species of Bangladesh," International Research Journal of Biological Sciences, vol. 3, no. 9, 2014.

[26] R. L. Semwal, R. K. Maikhuri, K. S. Rao, K. K. Sen, and K. G. Saxena, "Leaf litter decomposition and nutrient release patterns of six multipurpose tree species of Central Himalaya, India," Biomass and Bioenergy, vol. 24, no. 1, pp. 3-11, 2003.

[27] B.B.S. (Bangladesh Bureau of Statistics), Statistical Pocket Book of Bangladesh, Statistics Division, Ministry of Planning, Dhaka, Bangladesh, 2004.

[28] M. E. Kabir and E. L. Webb, "Can homegardens conserve biodiversity in Bangladesh?” Biotropica, vol. 40, no. 1, pp. 95103,2008

[29] J. S. Olson, "Energy storage and the balance of producers and decomposers in ecological systems," Ecology, vol. 44, pp. 322331, 1963.

[30] S. E. Allen, Chemical Analysis of Ecological Materials, Blackwell Scientific Publications, Oxford, UK, 1974.

[31] M. W. Weatherfourn, "PhenoI-hypochlorite reaction for determination of ammonia," Analytical Chemistry, vol. 39, no. 8, pp. 971-974, 1967.

[32] R. P. Timothy, M. Yoshiaki, and M. L. Carol, A Manual of Chemical and Biological Methods for Seawater Analysis, Pergamon Press, Oxford, UK, 1984.
[33] A. M. Cundell, M. S. Brown, R. Stanford, and R. Mitchell, "Microbial degradation of Rhizophora mangle leaves immersed in the sea," Estuarine and Coastal Marine Science, vol. 9, no. 3, pp. 281-286, 1979.

[34] A. Simlai and A. Roy, "Analysis of correlation between phytochemical and antimicrobial constituents of Ceriops decandra, a medicinal plant, from Indian Sundarban estuary," Journal of Medicinal Plants Research, vol. 6, pp. 4755-4765, 2012.

[35] H. Takeda, "Templates for the organization of soil animals communities in tropical forests," in Biodiversity and the Dynamics of Ecosystems, I. M. Turner, C. H. Diong, S. S. L. Lim, and P. K. L. Ng, Eds., Diwpa Series, pp. 217-226, Singapore, 1996.

[36] A. Ibrahima, P. Biyanzi, and M. Halima, "Changes in organic compounds during leaf litter leaching: laboratory experiment on eight plant species of the Sudano-guinea of Ngaoundere, Cameroon," Forest, vol. 1, pp. 27-33, 2008.

[37] A. Ibrahima, D. Gillon, and R. Joffre, "Leaf litter decomposition of Mediterranean tree species in relation to temperature and initial water imbibitions under microcosm experiment," Research Journal of Agriculture and Biological Sciences, vol. 6, pp. 32-39, 2010.

[38] H. Mahmood, O. Saberi, K. Misri, and B. Japar Sidik, "Nutrients dynamics associated with leaf litter degradation of Bruguieria parviflora (Whight and Arnold) at Kuala Selangor Mangrove Forest, Malaysia," Indian Journal of Forestry, vol. 30, pp. 325330, 2007.

[39] J. Bloomfield, K. A. Vogt, and D. J. Vogt, "Decay rate and substrate quality of fine roots and foliage of two tropical tree species in the Luquillo Experimental Forest, Puerto Rico," Plant and Soil, vol. 150, no. 2, pp. 233-245, 1993.

[40] H. A. Verhoef and B. Gunadi, "Decomposition dynamics and nutrient flow in pine forest plantation in Central Java," in Management of Tropical Plantation-Forests and Their Soil Litter System, M. V. Reddy, Ed., pp. 173-211, Science Publisher, Enfield, NH, USA, 2001.

[41] S. R. Isaac and M. A. Nair, "Biodegradation of leaf litter in the warm humid tropics of Kerala, India," Soil Biology \& Biochemistry, vol. 37, no. 9, pp. 1656-1664, 2005.

[42] S. F. J. Alvarez, G. R. Sanchez, I. Sanchez-Gallen, and J. A. Gonzalez-Iturbe, Methods for the Study of Primary Productivity and Decomposition in Terrestrial Communities, Department of Ecology, Faculty of Science, National Autonomous University of Mexico, 1992.

[43] C. Elevitch and K. Wilkinson, "Nitrogen fixing trees: multipurpose pioneers," 1998, http://www.agroforestry.net/free-publications/nitrogen-fixing-trees.

[44] H. Mahmood and O. Saberi, "Micro-nutrient contents of field grown seedlings, saplings and trees of a mangrove species, Bruguiera parviflora (Wight and Arnold) in the Kuala Selangor Nature Park, Malaysia," Indian Forester, vol. 133, pp. 1057-1062, 2007.

[45] H. Mahmood, S. H. Limon, M. S. Rahman, A. K. Azad, M. S. Islam, and M. Khairuzzaman, "Nutrients (N, P and K) dynamics associated with the leaf litter of two agroforestry tree species of Bangladesh," iForest, vol. 2, pp. 183-186, 2009.

[46] B. Berg and R. Laskowski, Litter Decomposition: A Guide to Carbon and Nutrient Turnover, Elsevier Scientific Publishing, Amsterdam, The Netherlands, 2006.

[47] A. Hagen-Thorn, I. Varnagiryte, B. Nihlgård, and K. Armolaitis, "Autumn nutrient resorption and losses in four deciduous forest tree species," Forest Ecology and Management, vol. 228, no. 1-3, pp. 33-39, 2006. 
[48] L. Guo and R. E. H. Sims, "Eucalypt litter decomposition and nutrient release under a short rotation forest regime and effluent irrigation treatments in New Zealand: II. Internal effects," Soil Biology \& Biochemistry, vol. 34, no. 7, pp. 913-922, 2002.

[49] L. Herráez Ortega and M. L. Fernández Marcos, "Materialization of eucalyptus debris in two sites in NW Spain," in Proceedings of the International Symposium Managing Forest Soils for Sustainable Productivity, M. Madeira and P. Khanna, Eds., pp. 87-88, UTAD, Vila Real, Portugal, 2000.

[50] S. L. Tisdale, W. L. Nelson, J. D. Beaton, and J. L. Havlin, Soil Fertility and Fertilizers, Prentice Hall, New Delhi, India, 5th edition, 1993.

[51] K. DeFelice, Nitrogen in the Plant, University of Missouri Extension Press, 1993.

[52] B. S. Meyer, D. B. Anderson, R. H. Bohning, and D. G. Fratiane, Introduction To Plant Physiology, D. Van Nostrand, New York, NY, USA, 1973.

[53] Y. M. Lin, J. W. Liu, P. Xiang, P. Lin, Z. H. Ding, and L. Da Silveira Lobo Sternberg, "Tannins and nitrogen dynamics in mangrove leaves at different age and decay stages (Jiulong River Estuary, China)," Hydrobiologia, vol. 583, no. 1, pp. 285-295, 2007. 

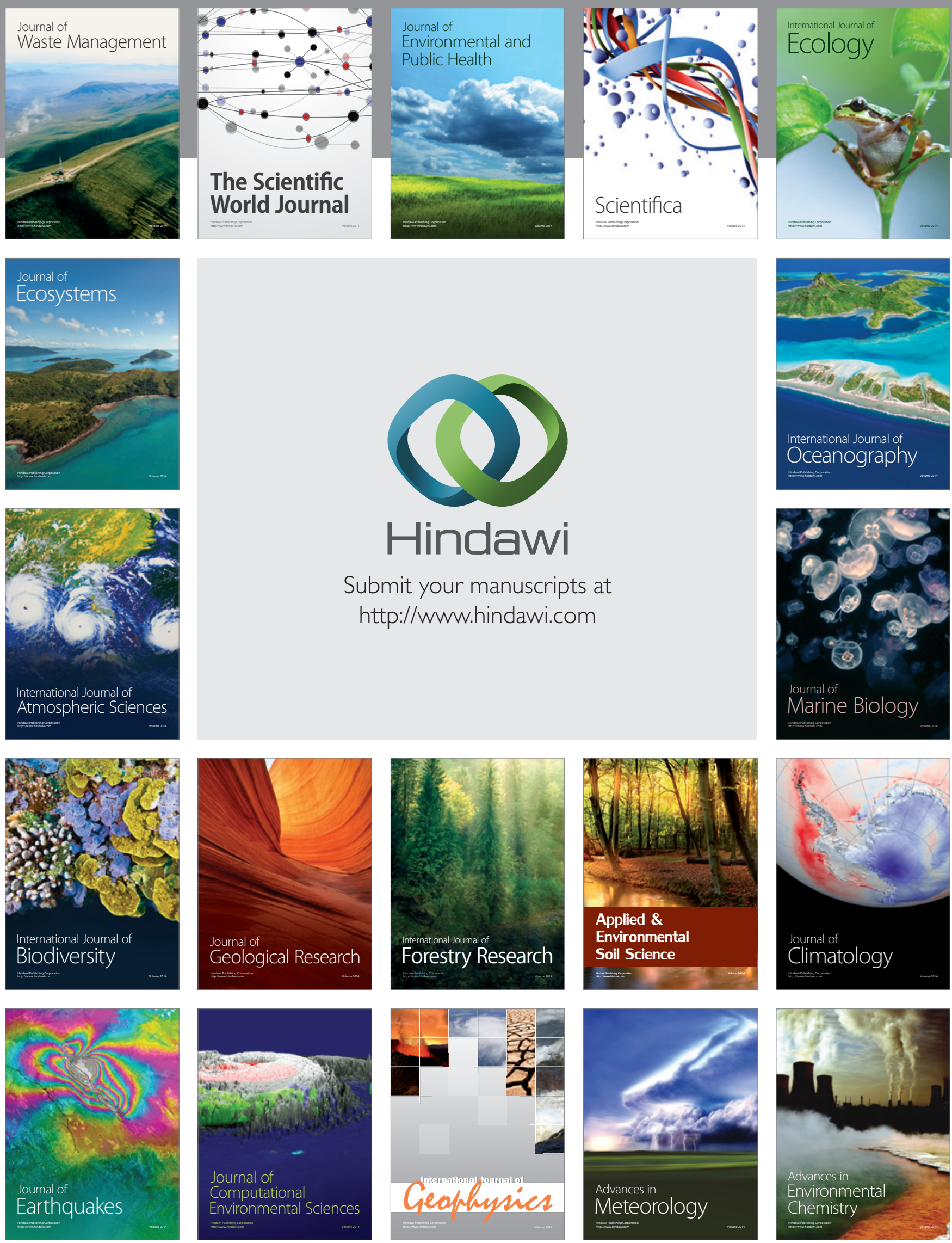